\title{
Catalyic Activity of Ruthenium(III) and Palladium(II) Complexes of 2- Methylbenzimidazole (Mebzlh) Encapsulated in Zeolite-Y and ZSM-5 for Liquid Phase Hydroxylation of Phenol
}

B P Nethravathi* and K N Mahendra†

\section{Abstract}

Ruthenium(III) and palladium(II) complexes of 2methylbenzimidazole (Mebzlh) ligand encapsulated in the super cages of zeolite-Y and ZSM-5 have been synthesized and characterized by various physicochemical measurements. A suitable reaction condition has been optimized for [Ru(Mebzlh) $]-Y$ by considering the effect of various parameters such as different solvents, concentration of substrate, reaction time and amount of oxidant etc., for the maximum conversion of phenol to a mixture of catechol and hydroquinone. The results obtained showed that selectivity for the catechol formation is ca. 85\%, even though the conversion of phenol varies in the order $[\mathrm{Ru}(\mathrm{Mebzlh})]-\mathrm{Y}(35 \%)>$

* Department of Chemistry, Christ University, Bangalore 560029, INDIA. nethravathi.p@christuniversity.in

† Department of Studies in Chemistry, Bangalore University, Bangalore 560001, INDIA. knmahendra@gmail.com 
[Pd(Mebzlh)]-Y (15\%) > [Ru(Mebzlh)]- ZSM-5(10\%) > [Pd(Mebzlh)]- ZSM-5 (2\%) after $6 \mathrm{~h}$ of reaction time.

Keywords: Encapsulation; zeolite-Y; ZSM-5; hydrogen peroxide decomposition; oxidation of phenol

\section{Introduction}

Nowadays the research in the area of heterogeneous catalysts is gaining importance because of the problems involved with homogeneous catalysts. The optimization of already known synthetic procedures by the possibility of performing reactions with very high yield by reducing by-products and with limited use of solvents is gaining lot of importance [1]. Generally such a reaction requires the presence of a catalyst which can selectively break the chemical bonds and form the new chemical bonds. Homogeneous catalysts were designed for such type of organic reactions but they require large quantities of solvents and difficult to recover the products. The substitution of such homogeneous catalysts with anchored solid supports is economical and reduces the environmental problems [2]. A great deal of research has been done on solid catalysts by considering their chemical and thermal stability, micro and mesoporosity. A heterogeneous catalyst can be obtained by encapsulating [ship-in-a-bottle] inside the pore of zeolite or by anchoring or tethering them to inert supports [3]. The ship-in-a-bottle approach is convenient and ideal, because the complex, once formed inside the cages of zeolite, is too large to diffuse out and is not lost in the liquid phase reaction. These encapsulated zeolites are the most important heterogeneous catalysts used in the petrochemical industry and in the synthesis of fine chemicals. Various transition metal complexes of Schiff bases and phthalocyanines have been encapsulated in zeolite- $\mathrm{Y}$ and their catalytic activity has been studied in the decomposition of $\mathrm{H}_{2} \mathrm{O}_{2}$ and tert-butyl hydroperoxide, oxidation of phenols, cyclohexanol, cyclohexene and other related reactions [4-9]. The liquid phase hydroxylation of phenol using simple oxidant like molecular oxygen and $\mathrm{H}_{2} \mathrm{O}_{2}$ is industrially important reaction. Both homogeneous and heterogeneous processes were known for the hydroxylation of phenol. The zeolite encapsulated metal complexes have considerable importance in this regard. 
In the present work, ruthenium(III) and palladium(II) complexes of 2-methylbenzimidazole (Mebzlh, I) are encapsulated in zeolite-Y and ZSM-5 and their catalytic activity for the liquid phase hydroxylation of phenol has been studied. To our knowledge, there are no reports so far of using encapsulated benzimidazole complexes of ruthenium and paladium inside H-Z-Y and H-ZSM5 for the hydroxylation of phenol. A suitable reaction condition has also been optimized to get maximum conversion of phenol.

\section{Experimental}

\subsection{Materials}

Zeolite H-Y and H-ZSM-5 were purchased from Sud-Chemie, Mumbai. LR-Grade acetone was purified according to literature methods [10]. Analytical grade ruthenium chloride and palladium chloride, Phenol and hydrogen peroxide $(30 \%)$ were purchased from Merck and were used as such. The ligand, 2-methyl benzimidazole was prepared according to the literature method [11].

\subsection{Characterisation}

Metal contents in the encapsulated complexes were measured by using Perkin-Elmer model ICP instrument. Surface area measurements were carried out by the BET method on a NOVA1000 Ver.3.70 instrument. TGA was recorded on a NETZSCH STA 409 PG/PC in flowing air and He atmosphere. X-ray diffraction patterns were recorded on a Philips Analytical X-ray instrument with $\mathrm{CuKa}$ target. FT-IR spectra of the complexes were recorded as $\mathrm{KBr}$ pellets on a Nicolet 4000 spectrophotometer. UV-Vis spectra were recorded for the ligand in DMF and by diluting with $\mathrm{BaSO}_{4}$ for the neat complex and encapsulated complex on a Shimadzu UV-Vis-NIR model UV-3101P instrument. Products formed from the reactions in the catalytic activity studies were analyzed using a Shimadzu 14B gas chromatograph fitted with FID detector and BP-5 capillary column. 


\subsection{Preparation of zeolite encapsulated complexes}

$5 \mathrm{~g}$ of metal chloride salt was dissolved in acetone. To this solution taken in a $100 \mathrm{ml}$ round bottom flask, $11 \mathrm{~g}$ of calcined $\mathrm{H}-\mathrm{Y}$ or $\mathrm{H}-$ ZSM-5 was added. The mixture was refluxed with stirring for $12 \mathrm{~h}$ in an oil bath. The solid was filtered out and then washed with water till the washings were free of metal ions. It was dried in a hot- air oven at $150{ }^{\circ} \mathrm{C}$ for $24 \mathrm{~h}$. Then M-Y was treated with an acetone solution of $2.5 \mathrm{~g}$ of 2-methyl benzimidazole and refluxed with stirring for $24 \mathrm{~h}$ in an oil bath. The residue was filtered and extracted first with DMF then with acetone using the Soxhlet apparatus to remove the unreacted ligand and any free metal complex adsorbed on the zeolite surface. The resulting solution was treated with aq. $0.01 \mathrm{M} \mathrm{NaCl}$ solution and then stirred for $15 \mathrm{~h}$ to exchange the uncomplexed metal ions with sodium ions. Then, the zeolite- encapsulated complex was filtered, washed with distilled water to remove the chloride ions present and dried in a hot- air oven at $150{ }^{\circ} \mathrm{C}$ for $24 \mathrm{~h}$.

\section{Catalytic Activity Measurements}

\subsection{Decomposition of $\mathrm{H}_{2} \mathrm{O}_{2}$}

An aqueous solution of standard $30 \% \mathrm{H}_{2} \mathrm{O}_{2}(3.95 \mathrm{ml}, 5.53 \mathrm{~g})$ was added to $0.025 \mathrm{~g}$ catalyst and the reaction mixture was stirred for 1 and $2 \mathrm{~h}$ respectively, at room temperature. The catalyst was then separated out by filtration and washed with distilled water. The filtrate containing partially decomposed $\mathrm{H}_{2} \mathrm{O}_{2}$ and the washings were collected in a $250 \mathrm{ml}$ volumetric flask, and the contents were made up to $250 \mathrm{ml}$ with distilled water. Then $10 \mathrm{ml}$ of this solution was titrated with standard $\mathrm{KMnO}_{4}$ solution to estimate the unreacted $\mathrm{H}_{2} \mathrm{O}_{2}$ [12].

\subsection{Hydroxylation of phenol}

The catalytic reactions were carried out in a $50 \mathrm{ml}$ double-necked round bottom flask fitted with a water condenser and heated on an oil bath using a magnetic stirrer. In a typical reaction, Phenol (2.35 $\mathrm{g}, 0.025 \mathrm{~mol})$ and $30 \%$ aqueous $\mathrm{H}_{2} \mathrm{O}_{2}(19.8 \mathrm{ml}, 0.25 \mathrm{~mol}, 27.7 \mathrm{~g})$ were mixed in $2 \mathrm{ml}$ of $\mathrm{MeCN}$ solvent and the reaction mixture was heated in an oil bath with continuous stirring at $80{ }^{\circ} \mathrm{C}$. Then 2 
mmol catalyst was added and the reaction was considered to begin. Aliquots were withdrawn from the reaction mixture and analyzed, using a gas chromatograph.

\section{Results and Discussion}

\subsection{Synthesis and characterization of catalysts}

Synthesis of the metal complex in the cages of H-Y and H-ZSM-5 was carried out by the flexible ligand method [13]. The percentage of metal content in the encapsulated complex was measured by using ICP instrument. The percentages of metal content along with the colour and formulae of the complexes and surface area measurements are given in Table 1. Simple complexes of Mebzlh were also prepared for comparison of the physico-chemical properties of encapsulated complexes.

\begin{tabular}{lccllc}
\hline Compound & Colour & $\begin{array}{c}\text { Metal } \\
(\text { Wt \%) }\end{array}$ & & ${ }^{*} \mathbf{S}_{\text {BET }}$ & $\begin{array}{c}\text { Total Pore } \\
\text { volume }\end{array}$ \\
\hline H-Z-Y & White & & - & 25.8 & 0.105 \\
H-ZSM-5 & White & & - & 258.7 & 0.179 \\
{$[\mathrm{Ru}($ Mebzlh)]-Y } & Dark grey & 0.192 & & 14.5 & 0.025 \\
{$[\mathrm{Ru}($ Mebzlh)]-ZSM-5 Light grey } & 0.030 & & 122.6 & 0.081 \\
{$[\mathrm{Pd}($ Mebzlh)]-Y } & Off white & 0.006 & & 18.4 & 0.028 \\
{$[\mathrm{Pd}($ Mebzlh)]-ZSM-5 } & White & 0.008 & 64.1 & 0.092
\end{tabular}

${ }^{*} S_{\mathrm{BET}}=$ Specific surface area measured by BET method

Table 1: Percentage of metal, colour of encapsulated complex and their surface area measurement data

Thermal stability of the catalyst Thermal stability of the encapsulated complex was studied using TGA and DTG. Representative TGA and DTG graphs of [Ru(Mebzlh)]-Y complex is shown in Fig. 1. The weight loss and the group lost is also tabulated in Table 2. The weight loss of the encapsulated complexes is observed to be in two to three major stages in the broad temperature range, which is clearly evident from DTG curve. The first stage weight loss starts on increasing the temperature above 
$100^{\circ} \mathrm{C}$ and continues till around $250^{\circ} \mathrm{C}$ until the loss of all intrazeolite water. The second step weight loss starts immediately after first step and continues around $450^{\circ} \mathrm{C}$ until the loss of all coordinated water molecules along with the chloride ions. The presence of several water molecules in these encapsulated complexes is expected even after drying them to $150^{\circ} \mathrm{C}$. The second step weight loss occurs in a wide temperature range of about 400 to $700^{\circ} \mathrm{C}$ and is due to the slow decomposition of the ligand.

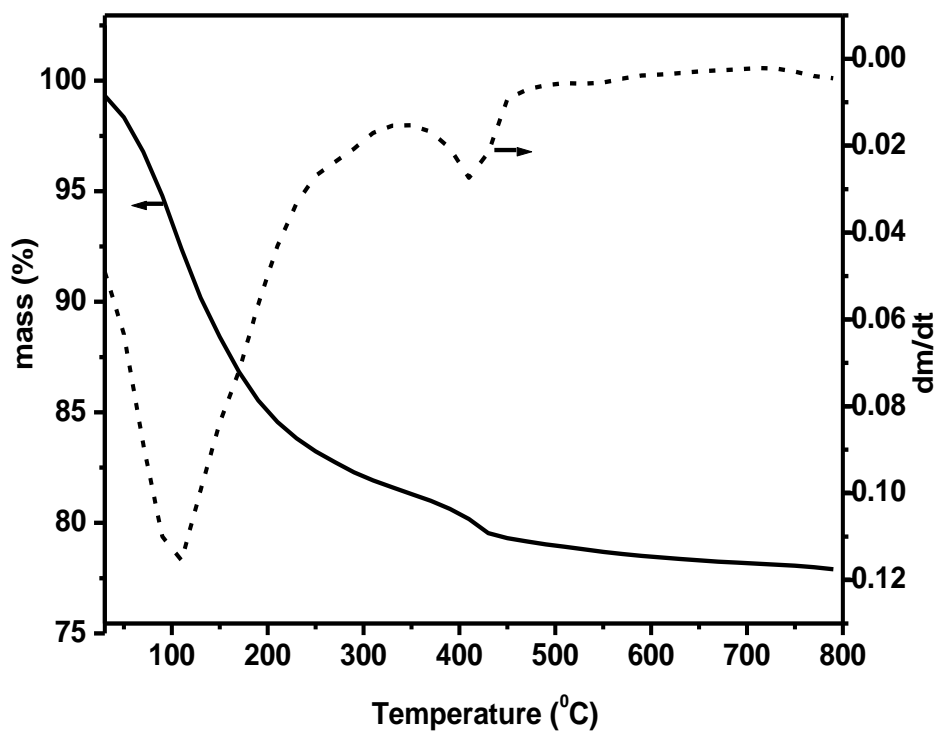

Fig. 1. TGA(_) and DTG(- - - ) Curves for [Ru(Mebzlh)]-Y

A very small weight percentage loss indicates the presence of only small amounts of metal complex in the zeolite cavities [14]. This is in agreement with the low percent of metal content measured. 


\begin{tabular}{lccl}
\hline Catalyst & $\begin{array}{c}\text { Temperature } \\
\text { range }\left({ }^{\mathbf{0}} \mathbf{C}\right)\end{array}$ & $\begin{array}{c}\text { weight loss } \\
(\%)\end{array}$ & Group lost \\
\hline$[\mathrm{Ru}($ Mebzlh) $]-\mathrm{Y}$ & $90-230$ & 14.0 & $\mathrm{nH}_{2} \mathrm{O}$ \\
& $230-450$ & 4.0 & $\mathrm{H}_{2} \mathrm{O}+\mathrm{Cl}-\mathrm{L}$ \\
{$[\mathrm{Ru}($ Mebzlh) $]-Z S M-5$} & $90-200$ & 4.0 & $\mathrm{nH}_{2} \mathrm{O}$ \\
& $200-390$ & 2.5 & $\mathrm{H}_{2} \mathrm{O}+\mathrm{Cl}$ \\
& $390-850$ & 1.0 & $\mathrm{~L}$ \\
{$[\mathrm{Pd}($ Mebzlh) $]-\mathrm{Y}$} & $90-220$ & 20.0 & $\mathrm{nH}_{2} \mathrm{O}$ \\
& $220-600$ & 5.0 & $\mathrm{H}_{2} \mathrm{O}+\mathrm{Cl}-+\mathrm{L}$ \\
{$[\mathrm{Pd}($ Mebzlh) $]-Z S M-5$} & $90-230$ & 4.0 & $\mathrm{nH}_{2} \mathrm{O}$ \\
& $230-450$ & 2.5 & $\mathrm{H}_{2} \mathrm{O}+\mathrm{Cl}^{-}$ \\
& $450-650$ & 1.2 & $\mathrm{~L}$ \\
\hline
\end{tabular}

Table 2: Thermogravimetric analysis data of catalysts

\section{Powder X-Ray diffraction studies}

The powder X-ray diffraction patterns of H-Y, H-ZSM-5 and of the encapsulated complexes were recorded at $2 \theta$ values between 5 to $80^{\circ}$. Essentially similar patterns were noticed for the encapsulated complexes as compared to H-Y and H-ZSM-5, though a slight change in the intensity of the bands was seen. These observations indicate retainment of the crystalline nature of the zeolite even after the encapsulation of the complex. No new peaks were detected in the encapsulated complex due to low percent loading of metal complexes.

\section{Infrared spectral studies}

The IR spectra (in $\mathrm{KBr}$ ) of the neat complex and encapsulated complexes are similar to the spectra of the uncoordinated ligand, except for minor shifts in the positions of some of the bands and some changes in their intensities due to coordination (Table 3). The complex shows a broad band around $3193 \mathrm{~cm}^{-1}$ assign to $\mathrm{v}_{\mathrm{N}-\mathrm{H}}$. The $\mathrm{v}_{\mathrm{C}=\mathrm{N}}$ and $\mathrm{v}_{\mathrm{C}=\mathrm{C}}$ vibrations are very close and occur around $1626 \mathrm{~cm}^{-1}$, this band is at a slightly lower frequency when compared to that observed in the ligand spectrum $\left(1631 \mathrm{~cm}^{-1}\right)$. The band around 
$1584 \mathrm{~cm}^{-1}$ is assigned to the $\mathrm{N}-\mathrm{H}$ inplane bending. $\mathrm{v}_{\mathrm{C}-\mathrm{N}}$ and $\delta_{\mathrm{N}-\mathrm{H}}$ appear around $1326 \mathrm{~cm}^{-1}$. The bands around 1414, 1275, 1062, 752, 633 and $447 \mathrm{~cm}^{-1}$ are assigned to benzimidazole ring vibrations. The assignments are tentative and have been made on the basis of similar assignments described earlier[15, 16].

\begin{tabular}{lcclc}
\hline Compound & $\mathrm{v}_{\mathrm{N}-\mathrm{H}}$ & $\mathrm{v}_{\mathrm{C}=\mathrm{N}} / \mathrm{v}_{\mathrm{C}=\mathrm{C}}$ & $\begin{array}{c}\text { N-H inplane } \\
\text { bending }\end{array}$ & $\mathrm{v}_{\mathrm{C}-\mathrm{N} / \delta_{\mathrm{N}-\mathrm{H}}}$ \\
\hline Mebzlh & 3210 & 1631 & 1512 & 1310 \\
{$[\mathrm{Ru}($ Mebzlh) } & 3193 & 1626 & 1584 & 1326 \\
{$[\mathrm{Ru}($ Mebzlh) $]-\mathrm{Y}$} & - & 1625 & 1529 & 1452 \\
{$[\mathrm{Ru}($ Mebzlh) $]-Z S M$} & 3115 & 1652 & 1558 & 1378 \\
{$[\mathrm{Pd}($ Mebzlh) $]$} & 2787 & 1619 & 1563 & 1450 \\
{$[\mathrm{Pd}($ Mebzlh) $]-\mathrm{Y}$} & 3133 & 1642 & 1515 & 1452 \\
{$[\mathrm{Pd}($ Mebzlh) $]-Z S M$} & 3105 & 1631 & 1574 & 1412 \\
\hline
\end{tabular}

Table 3: IR spectral data $\left(\mathrm{cm}^{-1}\right)$ of ligand, neat and encapsulated complexes

\section{Electronic spectral studies}

Electronic spectra for the ligand and the neat complex have been recorded in DMF and DRS were recorded in $\mathrm{BaSO}_{4}$ for the encapsulated complex and the data are listed in Table 4. The electronic spectrum of the ligand exhibited a split peak at 274 and $279 \mathrm{~nm}$ due to the $\mathrm{n}-\pi^{*}$ transitions of the benzimidazole moiety. The neat ruthenium complex showed adsorption bands at 409, 521 and $609 \mathrm{~nm}$ that are assigned to ${ }^{2} \mathrm{~T}_{2 \mathrm{~g}} \rightarrow{ }^{4} \mathrm{~T}_{1 \mathrm{~g}},{ }^{2} \mathrm{~T}_{2 \mathrm{~g}} \rightarrow{ }^{4} \mathrm{~A}_{2 \mathrm{~g}}$ and ${ }^{2} \mathrm{~T}_{2 \mathrm{~g}} \rightarrow{ }^{2} \mathrm{~T}_{1 \mathrm{~g}}$ transitions, respectively. Their positions are typical of ruthenium(III) complexes with octahedral geometry [17]. The spectrum of $\left[\mathrm{Ru}\left(\right.\right.$ Mebzlh)] encapsulated complexes in $\mathrm{BaSO}_{4}$ displayed three bands. The neat palladium complexes showed absorption bands at $280 \mathrm{~nm}$ and $483 \mathrm{~nm}$ and are assigned to ligand to metal charge transfer transition and ${ }^{1} \mathrm{~A}_{1 \mathrm{~g}} \rightarrow{ }^{1} \mathrm{~B}_{1 \mathrm{~g}}$ transition respectively. In case of encapsulated $\mathrm{Pd}(\mathrm{Mebzlh})$ complex there is no absorption band in the visible region because of less metal content present. 


\begin{tabular}{lll}
\hline Compound & medium & $\lambda_{\max }(\mathrm{nm})$ \\
\hline Mebzlh & $\mathrm{DMF}$ & $241,274,279$ \\
{$[\mathrm{Ru}($ Mebzlh $)]$} & $\mathrm{BaSO}_{4}$ & $243,267,274,363,456,523$ \\
{$[\mathrm{Ru}($ Mebzlh $)]-Y$} & $\mathrm{BaSO}_{4}$ & $241,269,296,366,461,544$ \\
{$[\mathrm{Ru}($ Mebzlh) $]-Z S M$} & $\mathrm{BaSO}_{4}$ & $245,287,274,372,468,506$ \\
{$[$ Pd(Mebzlh) $]$} & $\mathrm{BaSO}_{4}$ & $243,271,280,293,384,483$ \\
{$[$ Pd(Mebzlh) $]-Y$} & $\mathrm{BaSO}_{4}$ & $241,268,274,311,397$ \\
{$[$ Pd(Mebzlh) $]-Z S M$} & $\mathrm{BaSO}_{4}$ & $242,269,275,295,381$
\end{tabular}

Table 4: Electronic spectral data of ligand and complexes

\subsection{Catalytic activity studies}

\section{Decomposition of $\mathrm{H}_{2} \mathrm{O}_{2}$}

Encapsulated complexes were tested for their catalytic activity towards the decomposition of $\mathrm{H}_{2} \mathrm{O}_{2}$. The percentage of $\mathrm{H}_{2} \mathrm{O}_{2}$ that reacted and the turnover frequency (TOF) at two different time intervals ( 1 and $2 \mathrm{~h}$ ) were measured. The results showed that the decomposition of $\mathrm{H}_{2} \mathrm{O}_{2}$ is slow up to $1 \mathrm{~h}(0.53$ to $2.18 \%)$ in all the cases and increases after $2 \mathrm{~h}$ with different trends. The percentage decomposition of $\mathrm{H}_{2} \mathrm{O}_{2}$ and the turn over frequency (TOF) are tabulated in Table 5. The data indicate that the encapsulated complex requires a relatively longer time to attain maximum equilibrium. Hence, increasing time of reaction is a very effective method of carrying out the oxidation reaction, with $\mathrm{H}_{2} \mathrm{O}_{2}$ as the source of oxygen.

\begin{tabular}{lcccc}
\hline${ }^{*}$ Catalyst & $\begin{array}{c}\text { Percentage of } \\
\mathrm{H}_{2} \mathrm{O}_{2} \text { reacted } \\
\text { After 1 h }\end{array}$ & $\begin{array}{c}\text { \#TOF } \\
\left(\mathrm{h}^{-1}\right)\end{array}$ & $\begin{array}{c}\text { Percentage of } \\
\mathrm{H}_{2} \mathrm{O}_{2} \text { reacted } \\
\text { After } 2 \mathrm{~h}\end{array}$ & $\begin{array}{c}\text { \#TOF } \\
\left(\mathrm{h}^{-1}\right)\end{array}$ \\
\hline$[\mathrm{Ru}($ Mebzlh) $]-\mathrm{Y}$ & 2.18 & 7.42 & 3.66 & 6.32 \\
{$[\mathrm{Ru}($ Mebzlh)]-ZSM-5 } & 0.53 & 11.45 & 3.0 & 32.66 \\
{$[\mathrm{Pd}($ Mebzlh) $]-\mathrm{Y}$} & 0.58 & 68.59 & 0.75 & 43.32 \\
{$[\mathrm{Pd}($ Mebzlh) $]-Z S M-5$} & 1.00 & 81.75 & 1.16 & 47.53 \\
\hline
\end{tabular}

${ }^{\#} \mathrm{TOF}=$ moles of the substrate converted per mole of the (metal) in the solid catalyst

Table 5: Turnover number for the decomposition of $\mathrm{H}_{2} \mathrm{O}_{2}$ 


\section{Hydroxylation of Phenol}

The catalytic hydroxylation of phenol using different encapsulated complexes was studied as a function of time using $\mathrm{H}_{2} \mathrm{O}_{2}$ as oxidant and acetonitrile as solvent. Catechol and hydroquinone were obtained as the major products [Retention times for phenol, catechol and hydroquinone 8,13 and 15 min respectively) as shown below.

The minor products if any, was not detected in GC under the condition used herein.

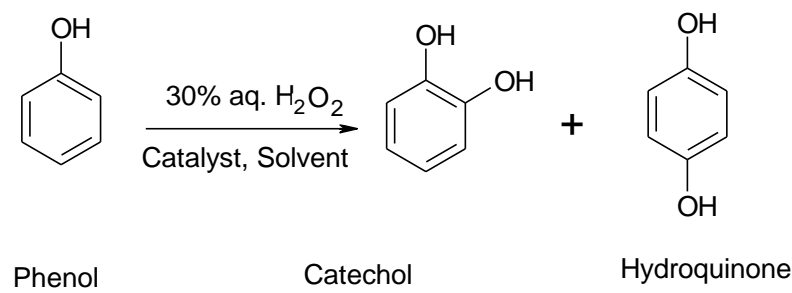

To have maximum transformation of phenol and better selectivity for catechol, the different parameters were optimized using [Ru(Mebzlh)]-Y.

The reaction was carried out for $6 \mathrm{~h}$ of reaction time with the optimized condition ( $2.35 \mathrm{~g}$ phenol, $4 \mathrm{ml} \mathrm{H}_{2} \mathrm{O}_{2}, 2.5 \mathrm{mmol}$ catalyst in $2 \mathrm{ml}$ of acetonitrile at $80{ }^{\circ} \mathrm{C}$ ) for all the catalysts. The effect of different catalysts for the conversion of phenol is represented in Fig. 2. 


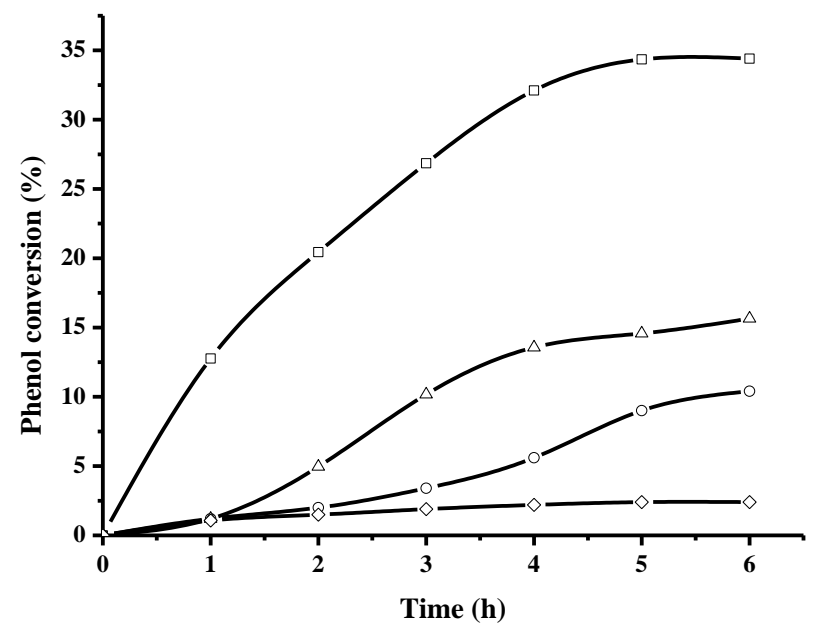

Fig. 2. Effect of various catalysts on phenol hydroxylation ( $\square)[\mathrm{Ru}($ Mebzlh) $]-Y, \quad(\mathrm{O})$ [Ru(Mebzlh)]- ZSM-5 , ( $\Delta)$ [Pd (Mebzlh)]- Y and $(\diamond)$ [Pd (Mebzlh)]- ZSM-5

\section{Recycling efficiency}

The recycling efficiency of the catalyst [Ru(Mebzlh)]-Y is checked for hydroxylation of phenol under optimized reaction conditions. The observed percentage of phenol conversion and selectivity to catechol and hydroquinone are given in Table 6. The catalytic activity of the catalyst decreased very slowly due to very slow leaching of the metal complex. Thus, the catalyst has a good recycling efficiency. The metal estimation test showed very negligible amount of metal concentration loss in the reaction mixture.

\begin{tabular}{lrccc}
\hline Catalyst & \multicolumn{5}{c}{ Number of cycles } \\
{$[\mathrm{Ru}($ Mebzlh)]-Y } & Fresh & 1 & 2 & 3 \\
\hline Phenol conversion (\%) & 35 & 33 & 34 & 32 \\
Catechol selectivity (\%) & 85 & 83 & 85 & 82 \\
Hydroquinone selectivity (\%) & 15 & 17 & 15 & 18 \\
\hline
\end{tabular}

Table 6: Recycling efficiency 


\section{Conclusions}

Encapsulation of ruthenium(III) and palladium(II) complexes in Z$\mathrm{Y}$ and ZSM-5 zeolite cavities can be conveniently carried out by the flexible ligand method. Physical and spectral studies of the encapsulated zeolites clearly indicate that the encapsulation of complex occurs in the cages of zeolite. The encapsulated complexes are active catalysts for the decomposition of $\mathrm{H}_{2} \mathrm{O}_{2}$ and for the oxidation phenol with good selectivity for catechol and hydroquinone. A blank reaction was also conducted with the optimized condition and a very less percentage of phenol conversion $(2 \%)$ was observed. In all the catalysts the selective is much more for catechol than hydroquinone (Table 7). Fig.3. indicates the percentage formation of catechol and hydroquinone products. The IR and UV spectra of fresh and used catalysts are nearly identical with not much loss in intensity of the peaks, which indicates that these zeolite encapsulated catalysts can be reused for catalytic study.

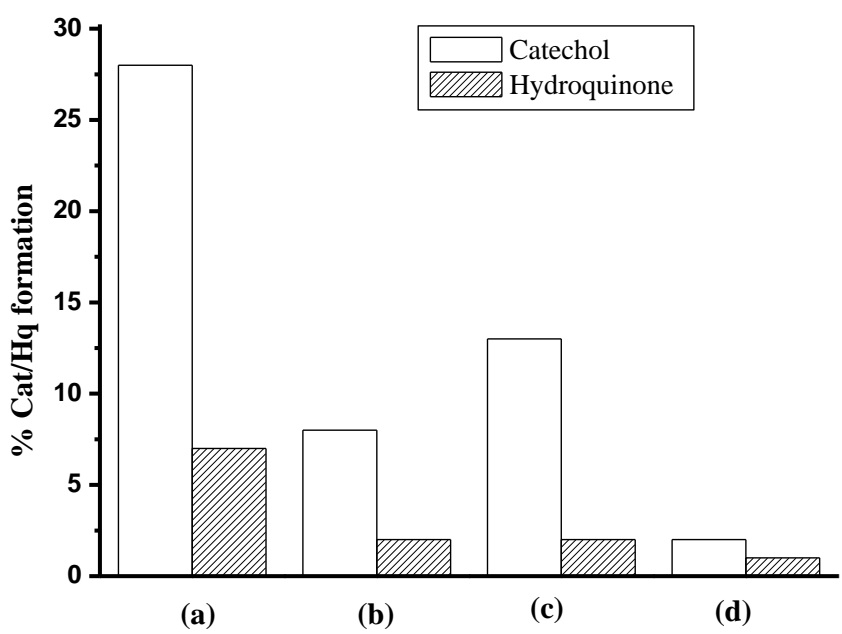

Fig 3: Percentage formation of Catechol and hydroquinone for (a) $[\mathrm{Ru}($ Mebzlh)]-Y, (b) [Ru(Mebzlh)]- ZSM-5 , (c) [Pd (Mebzlh)]- Y and (d) [Pd (Mebzlh)]- ZSM 


\begin{tabular}{|l|l|l|l|l|}
\hline $\begin{array}{l}\text { Sl. } \\
\text { No }\end{array}$ & Catalyst used & $\begin{array}{c}\text { Phenol } \\
\text { conversio }\end{array}$ & \multicolumn{2}{|c|}{ Diphenol formation (\%) } \\
\hline \hline & & $\mathrm{n}$ & Catechol (\%) & $\begin{array}{c}\text { Hydroquinone } \\
(\%)\end{array}$ \\
\hline \hline 1 & {$[\mathrm{Ru}(\mathrm{MeBzlH})]-\mathrm{Y}$} & 35.05 & 28.07 & 6.98 \\
2 & {$[\mathrm{Pd}(\mathrm{MeBzlH})]-\mathrm{Y}$} & 14.85 & 12.92 & 1.93 \\
3 & {$[\mathrm{Ru}(\mathrm{MeBzlH})]-Z S M$} & 10.01 & 8.08 & 1.93 \\
4 & {$[\mathrm{Pd}(\mathrm{MeBzlH})]-\mathrm{ZSM}$} & 2.09 & 1.06 & 1.03 \\
\hline
\end{tabular}

Table 7: Percentage formation of Catechol and hydroquinone

\section{Acknowledgement}

The authors gratefully acknowledge Prof. B.S. Jaiprakash, former Principal, Bangalore Institute of Technology, Bangalore for recording surface area measurements and the financial support from UGC-DRS Programme, New Delhi.

\section{Dedication}

This paper is dedicated to Late Dr. N. Shashikala, Reader, Dept. of Chemistry, Bangalore University, Bangalore.

\section{References}

[1] Masoud Salavati-Nisari, Shirin Shafaie-Arani, MohammadReza Ganjali, and Parviz Norouzi, "Synthesis, characterization and catalytic oxidation of cyclohexene with molecular oxygen over host (zeoliteY)/guest (nickel(II) complexes of $\mathrm{R}_{2}[12] 1,3$-diene $\mathrm{N}_{2} \mathrm{O}_{2}$ and $\mathrm{R}_{2}$ [13]1,4dieneN $\mathrm{N}_{2} \mathrm{O}_{2} ; \mathrm{R}=\mathrm{H}$, Me, $\left.\mathrm{Ph}\right)$ nanocatalyst $\left(\mathrm{HGN}^{\prime}\right)$, "Tranistion Metal Chemistry, Vol. 31, pp. 964-969, 2006.

[2] S. M. George (ed.), "Introduction: Heterogeneous Catalysis", Chem. Rev.,vol 95, pp ,475-476, 1995.

[3] W. P.Griffith, and J.M.Joliffe, "Dioxygen Activation and Homogeneous Catalytic Oxidation", Elsevier, Amsterdam, 1991.

[4] C. R. Jacob, S.P. Varkey, and P. Ratnasamy, "Selective oxidation over copper and manganese salens encapsulated in zeolites," Microporous Mesoporous Mater., vol. 22, pp, 465-474. 1998.

[5] C.R. Jacob, S.P. Varkey, and P. Ratnasamy, "Zeolite-encapsulated copper $\left(\mathrm{X}_{2}\right.$-salen) complexes", Appl. Catal. A: Gen., vol. 168, pp,353-364, 1998. 
[6] S.Deshpande, D.Srinivas, and P. Ratnasamy, "EPR and Catalytic Investigation of $\mathrm{Cu}($ Salen) Complexes Encapsulated in Zeolites" J. Catal., vol. 188, pp, 261-269, 1999.

[7] Vicente Rives, Amit Dubey, and Srinivasan Kannan , "Synthesis, characterization and catalytic hydroxylation of phenol over CuCoAl ternary hydrotalcites"', Phys. Chem.Chem.Phys., vol. 3, pp, 4826-4836, 2001.

[8] C. Ratnasamy, A. Murugkar, S. Padhye, and S.A. Pardhy, "ZeoliteEncapsulated $\mathrm{Cu}(\mathrm{II})-\mathrm{SALEN}$ Complex as a Catalyst for Oxidation of Cyclohexanol", Indian J. Chem., vol. 35A, pp, 1, 1996.

[9] R. A. Sheldon, I.W.C.E. Arends, A. and Dijksman, "New developments in catalytic alcohol oxidations for fine chemicals synthesis" Catal.Today, vol. 57, pp, 157-166, 2000.

[10] D.D Perrin, W.L.F Armanego, and D.R Perrin, "Purification of Laboratory Chemicals," Pergamon Press, Oxford, 1966.

[11] D.W. Hein, R.J. Alheim, and J. J. Leavitt, "The Use of Polyphosphoric Acid in the Synthesis of 2-Aryl- and 2-Alkyl-substituted Benzimidazoles, Benzoxazoles and Benzothiazoles", J.Amer.Chem.Soc.vol. 79, pp, 427-429, 1957.

[12] J. Bassett, R.C. Denney, G.H. Jeffery and J. Mendham, Vogel's Textbook of Quantitative Inorganic Analysis, fourth ed., Longman Scientific and Technical, England, 1978.

[13] Fethi Bedioui, "Zeolite-encapsulated and clay-intercalated metal porphyrin, phthalocyanine and Schiff-base complexes as models for biomimetic oxidation catalysts: an overview" Coordination Chemistry Reviews, vol. 144, pp, 39-68, 1995.

[14] Mannar R. Maurya, Salam J.J. Titinchi, and Shri Chand, "Catalytic activity of chromium(III), iron(III) and bismuth(III) complexes of 1,2-bis(2hydroxybenzamido)ethane $\left(\mathrm{H}_{2}\right.$ hybe) encapsulated in zeolite- $\mathrm{Y}$ for liquid phase hydroxylation of phenol" J. Mol. Catal. A: Chem., vol. 214, pp, 257264, 2004.

[15] M. M. Cordes, J. L. Walter, "Infrared and Raman studies of heterocyclic compounds-II Infrared spectra and normal vibrations of benzimidazole and bis-(benzimidazolato)-metal complexes", Spectrochim. Acta,vol. 24A, pp, 1421-1435, 1968.

[16] T. J. Lane, C.S.C. I Nakagawa, J.L. Walter, C.S.C and A.J. Kandathil, "Infrared Investigation of Certain Imidazole Derivatives and their Metal Chelates" Inorg.Chem., vol. 1, pp, 267-276, 1962.

[17] A.B.P. Lever, Inorganic Electronic Spectroscopy, Elsevier, New York, 1984. 